\title{
USING OF INFORMATION TECHNOLOGIES TO IMPROVE THE SPATIAL UNDERSTANDING OF STUDENTS
}

\author{
Olafs Vronskis ${ }^{1}$, Natālija Vronska ${ }^{2}$ \\ 1- Latvia University of Agriculture, Faculty of Engineering \\ Jelgava, J. Čakstes bulv. 5; e-mail: olafs.vronskis@1lu.lv, 63080701 \\ 2- Latvia University of Agriculture, Faculty of Information Tehnologies \\ Jelgava, Lielā 2; e-mail: natalja.vronska@1lu.lv, 63005707
}

\begin{abstract}
It is possible to improve the development of students' spatial thinking with various information technologies. We can improve students understanding with three dimensional models, created in the $C A D$ program and special processing it in PowerPoint in the program, together with drafting in three planes. Gradually solving tasks in planes and explaining it in three dimensional models, the solution of concrete task is much clearer, because it is possible to look a situation together in planes and 3D models.

The students of three faculties were polled that cognize the students' opinions about teachers teaching methods in descriptive geometry lessons and analyze spatial understanding of students.

A possibility to use information technologies to improve a descriptive geometry lectures have been researched in this work.

The most important information about working out methodological materials has been generalized in discussion part.

The results of research show that lectures with information technologies using improve students' understanding of solved tasks during the lectures.
\end{abstract}

Key words: descriptive geometry, handouts, multimedia, spatial understanding.

\section{Introduction}

Spatial thinking is especially developed in many specialists preparation for practical activities. The high level of spatial thinking is necessary for many technical subjects understanding at different learning steps.

The disadvantages in spatial thinking development are seen in mastering of descriptive geometry.

So there has been worked out the methodology for descriptive geometry mastering in learning process using multimedia technologies.

These technologies allow not only to master learning material, but as well to improve the students' level of understanding during the lecture. Using multimedia technologies it is possible to move spatial objects and so to make the lecture more perceived and understandable in short time. Multimedia technologies are more often used in learning process and they can be considered as an integral part of learning process.

So it is necessary to change learning methods including multimedia technologies into the learning process. In the descriptive geometry it is possible to animate or move spatial models and accordingly to depict on the screen.

Research aim: to clarify the multimedia technologies influence on students' spatial understanding.

Research hypothesis: using multimedia technologies at descriptive geometry lectures students' spatial understanding has been improved.

\section{Materials and methods}

In the research participated to 172 students from Latvia University of Agriculture Forest Faculty, Faculty of Engineering and Faculty of Rural Engineering. 
In experiment were two groups: control and experimental. In control group a themes of descriptive geometry (Projection of a point; projection of a line; projection of a plane; relations between a point, a line and a plane; change of projekction planes; intersection of a line (plane) and a plane; intersection of a plane and a surface; intersection of a surfaces) explained on a blackboard, and in experimental group - use of multimedia.

Author use Auto CAD and PowerPoint software for lecture development. Materials have published at E-studies environment, too. Author has made the combated descriptive geometry study courses with interactive e-learning elements.

When the students of each group had write opinion survey about descriptive geometry themes, which has been considered during the lecture. Opinion survey is created for check of understanding a concrete theme of a lesson.

The results of research are processed by software SPSS. In order to find out a statistically significant difference between control and experimental groups was conducted MannWhitney test between groups.

\section{Results}

At first, it was found out how substantially are differences of understanding in descriptive geometry between control and experimental groups, conducted Mann-Whitney test between groups.

The hypothesis was advanced, that understanding in descriptive geometry is equal in both groups.

Table 1 (understanding) result shows that comparing the data on two groups according to the grouping variable group, it can be concluded that there are significant differences between control and experimental groups $\mathrm{p}=0.000<0.05(\mathrm{p}=95 \%)$.

So between control group and experimental group exist differences of understanding in descriptive geometry. On a figure 1 it is possible to see control and experimental groups percentage understanding of the concrete complete theme.

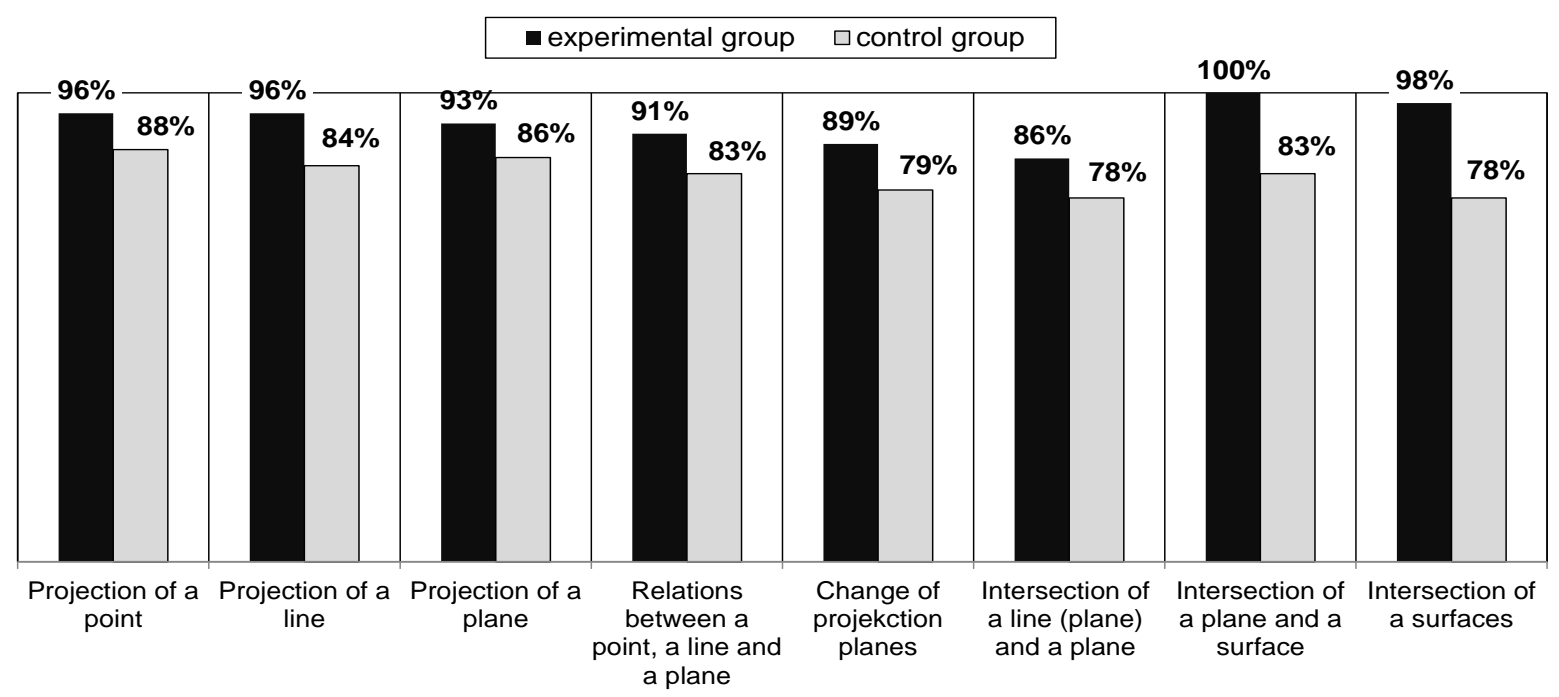

Fig. 1. Control and experimental groups differences of understanding

Secondly, was found out how substantially are differences of incomprehension in descriptive geometry between control and experimental groups.

The hypothesis was advanced, that incomprehension in descriptive geometry is equal in both groups. 
Table 1 (incomprehension) result shows that comparing the data on two groups according to the grouping variable group, it can be concluded that there are significant differences between control and experimental groups $\mathrm{p}=0.000<0.05(\mathrm{p}=95 \%)$.

Table 1 .

Test results

\begin{tabular}{|l|r|r|}
\hline & understanding & incomprehension \\
\hline Mann-Whitney U & 79206.000 & 2136.500 \\
Wilcoxon W & 185236.000 & 5539.500 \\
Z & -7.709 & -3.961 \\
Asymp. Sig. (2-tailed) & 0.000 & 0.000 \\
\hline
\end{tabular}

So between control group and experimental group exist differences of incomprehension in descriptive geometry.

\section{Discussion}

Spatial thinking can be considered as a mental peculiarity of any person which provides the orientation in the space - visible or imaginary [1].

Spatial thinking is a kind of mental activity, providing the forming of spatial images and using them in the process of fulfilling practical and theoretical tasks [2].

Spatial thinking is formed at all steps of ontogenesis under the influence of different teaching/ learning affects [3].

Developing of imagination is the most important condition to master the skill of descriptive geometry and reading the draught and graphic activity in general. At the same time teaching descriptive geometry is one of the most important means to develop imagination [4].

The most important principle directed to the learning process is the following: at the beginning of mastering new material of descriptive geometry students are taught the elementary methods, which are characterized by additional base on visual aids, and then the methodology has to provide changing the teaching ways so, that a student made images without any additional base, that is mentally, by imagination. The students' transition from activities with additional base to mental in the process of imagination reveals a regularity, which means, that in the process of mastering any knowledge a great role plays the transition from actual activities or activities with visual aids to mental ones, that is to activities in mind.

This transition should be done in time. If the students are taught the "visual" methods of learning activity too long, not including imagination, if can complicate the development of their spatial imagination [5].

Perception is a complicated system of receiving and transforming information, which provides the organism with an ability to reflect the objective reality and to take one's bearings in the surrounding world.

Visual perception includes various sources of information besides those, which are perceived by eyes, when we are looking at the object. In the process of perceiving, as a rule, is included the knowledge about object got from the previous experience and this experience is not limited by vision. It one more time underlines the active process of perception [6].

To form imagination it is necessary to master understanding, because understanding determines the content of image. Spatial imagination as regards to thinking is an initial base, condition of development, but at the same time forming the notions demands to master them, to master facts in advance. If can be said, that the process of forming spatial imagination about geometrical objects is realized on the base of knowledge about them [7].

Spatial thinking is one of thinking kinds which is characterized as the whole of cognitive skills. These skills include: declarative and perceiving forms of knowledge, as well various 
cognitive processes, which are used to transform and combine or to operate the knowledge in other way. In the base of cognitive process are included all knowledge, skills, experiences, which are used to think, discuss, solve problems, organize, plan and take the decision. Cognitive processes give a possibility to solve personal, social and international problem systematically, avoiding the repeated attempts and mistakes [8].

Spatial thinking as well as other kinds of thinking, is based on thinking operations, but its content is formed by spatial dimension. By thinking process is understood: analysis and synthesis, comparison, classification, systematization, generalization, abstraction, concretization.

Analysis is a thinking operation, which helps to break a phenomenon into smaller parts, separate elements or groups, and as a result to get much simpler phenomenon, a group of elements or parts which understanding by its sense is clear.

Conducting descriptive geometry lectures, it is necessary to provide a possibility to break a complicated spatial task into its smaller parts and as well to provide the usage of preliminary obtained knowledge and skills in fulfilling the corresponding parts task. For example, at lectures in which are considered complicated figures (Figure 3) it is necessary, first of all, to break it them into basic elements, that is, to consider what straight lines and planes this figure consists of, or what straight lines or planes are presented in the real size, or the angles formed by these planes or straight lines are in the real size (Figure 2); and only after that to start solving the task. Such task organization assists the improvement of spatial thinking, because is formed the deep understanding what angles, planes and straight lines mutual position, and only after that is analyzed in what kind of task fulfilling in addition to the concrete task soloing methods and ways we can use features of these basic elements.

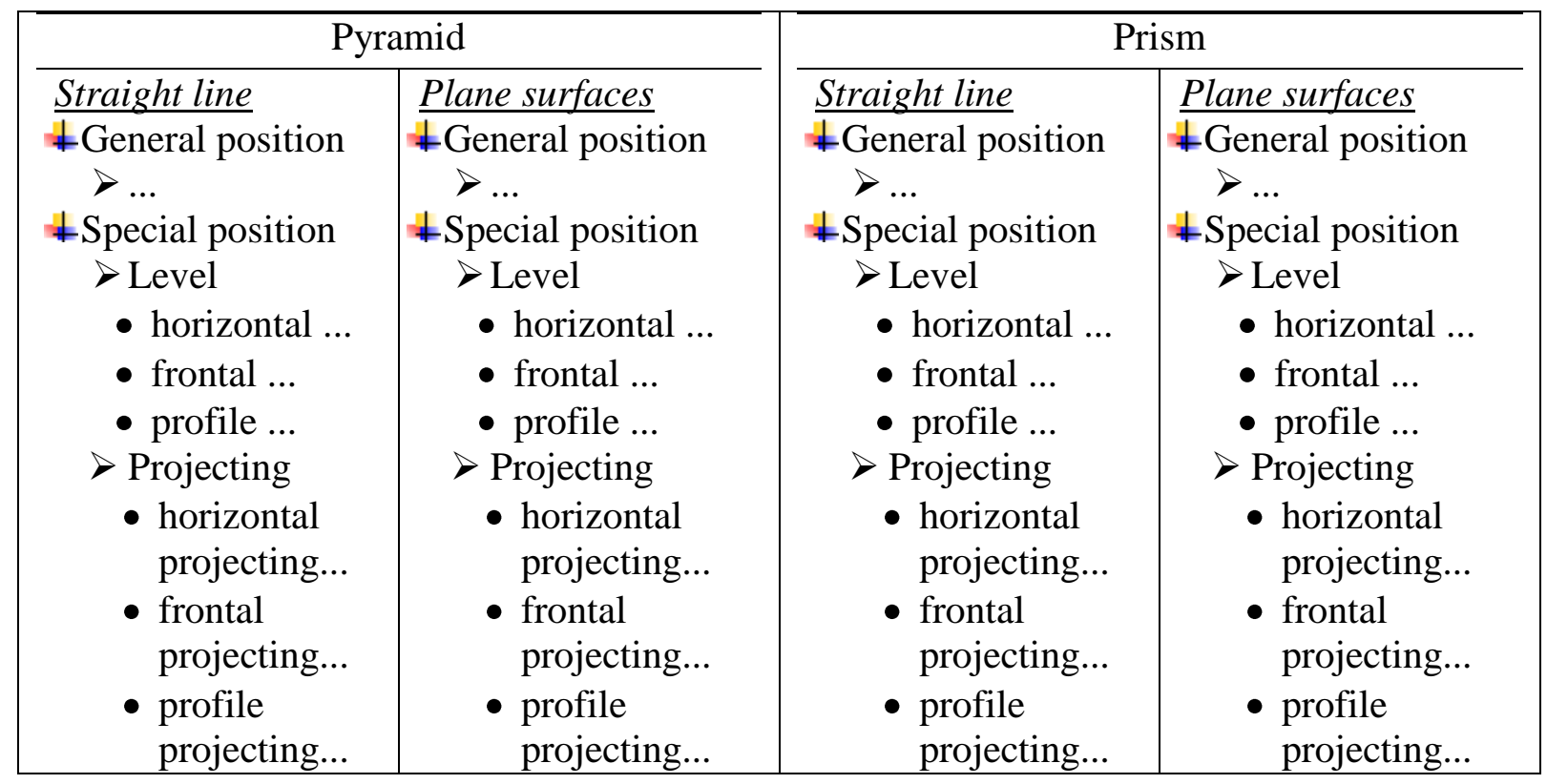

Fig. 2. Complicated figures break into basic elements 
Vronskis O., Vronska N. USING OF INFORMATION TECHNOLOGIES TO IMPROVE THE SPATIAL UNDERSTANDING OF STUDENTS

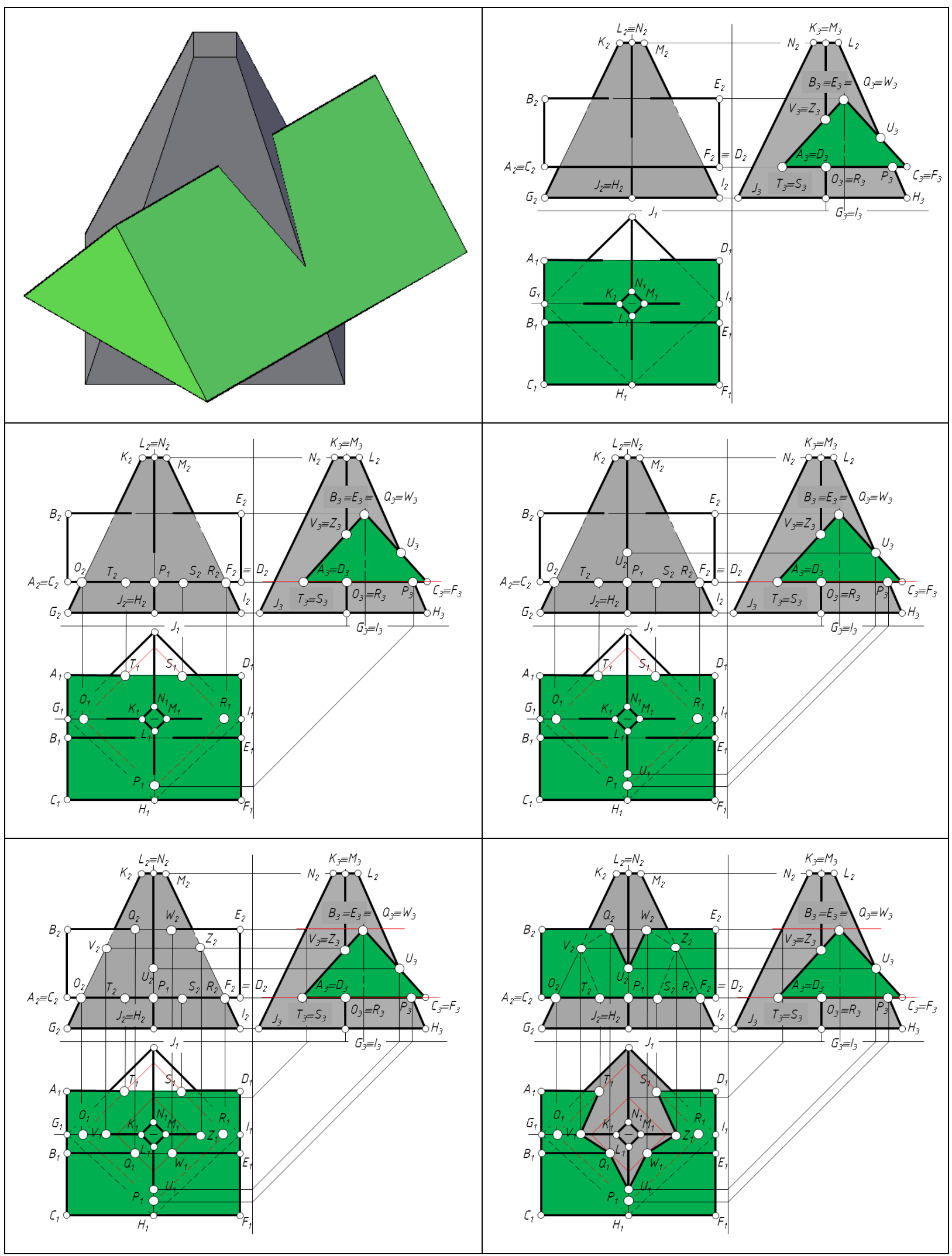

Fig. 3. Example of complicated figures 
For better observe bases of the theory - it in the form of definition should be told, passing significant words which to students should be entered in the definition (Figure 4).

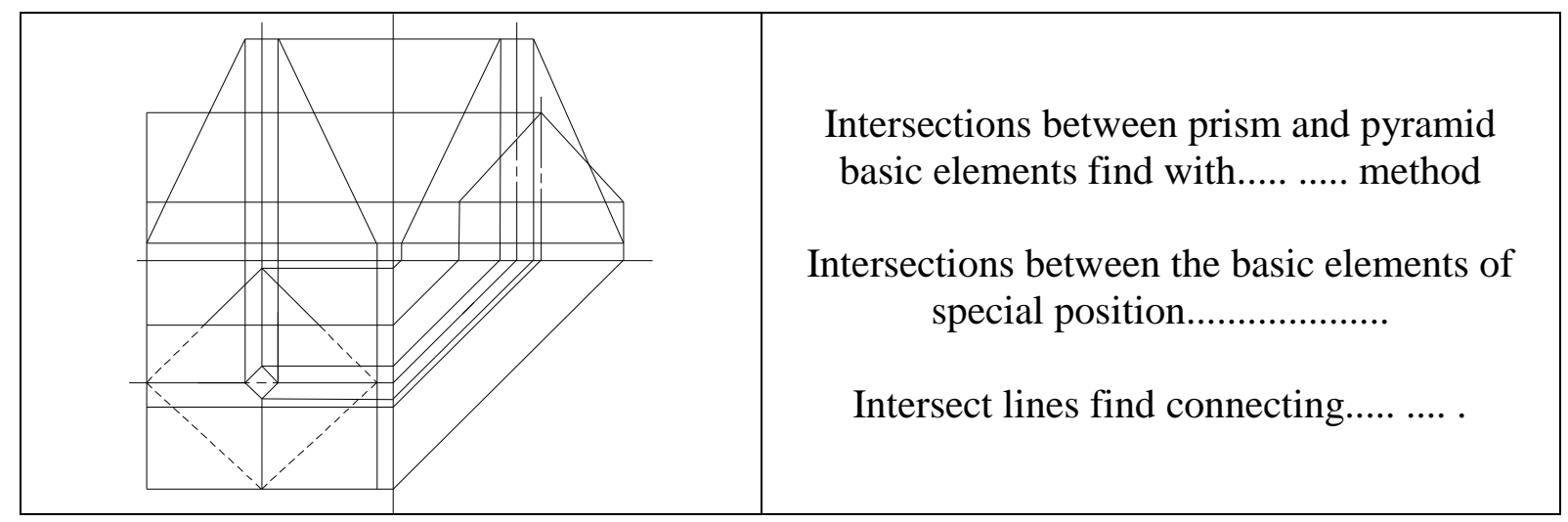

\section{Fig. 4. Definition of complicated figure solving}

These operations are better with handouts employed in lectures. Correspondingly, the thinking operation of synthesis has been revealed, which is interpretated as different phenomena, their parts or separate group elements combining into are operation or as well as the close interaction of these elements in one phenomenon.

Having considered above mentioned examples, we can see when during the synthesis operation are realized invisible spatial activities either in practice, forming the understanding about existing phenomena (angles a real size links), or, forming understanding about space. Separate activities, mastered knowledge and new skills are united, forming new skills by the quality, which include spatial thinking skills too.

Analysis and synthesis are realized with the help of other thinking operations. As one of those thinking operations is comparison, which is expressed as determination of compared objects, phenomena and facts. Also comparison is understood as the determining or reviewing of united criteria. To visualize the operations of comparison in the spatial context let us consider the same task. In this task it is necessary to review, that there are two cross points of basic elements, which are found not using special methods, because are crossing the special planes with the special straight line, the difference is only in the location of these basic elements. In one case are crossing the profiles of projected prism planes BCEF with the profile of pyramid straight line $\mathrm{LH}$, but in the second case are crossing the same profiles of projected prism planes ABDE with the front pyramid straight line GK. Both in the first and in the second case the cross point is looked for in the planes of profiled projections, because the prism profiles of projected planes are represented as a straight line. This kind of activity is expected to have definite difficulties, the realized comparison is happening in reflection and demands the great efforts of operative memory, and especially, if in the previous experience have not been understood the mutual features of planes and straight line positions. Before solving such kind of task there should both experience and skills to determine the cross point of basic elements. Classification is the next thinking operation, which is much more difficult than comparison, because it demands to unite objects, phenomena or operations into groups according to their similarities. When a student, comparing, have understood the essence of all projected, leveled and common basic elements positions, he is already able to classify them, and according to this classification to know, not comparing, that all cross points of projected planes with straight lines are seen in the planes of projections, in which these planes are reflected as straight lines or in front of which these planes are perpendicular. Classification gives a possibility to release the operative memory, and as a result to improve other mental activity. 
As well on the map the represented information is classified and reflected according to the group of space objects.

Systematization is similar to classification, which is expressed as dividing the whole into parts. Systematization in the spatial dimension provides the mutual ties and consequences of regularities in general, and thus forming the necessary task or thinking algorithm and having understood it, is formed a possibility to look at the fulfilling task from the other point of view. Generalization as a thinking operation is unification according to common features. And in the result the solving of different spatial problem situations, the algorithm can be similar.

Abstraction as one of the most difficult phenomenon of thinking process, because is connected with clearing up of essential features, and in the result are formed regularities. Fulfilling the task, in the base of which is the comprehension of know spatial regularities promotes more perfect understanding of definite question, and thus appears a possibility to form new knowledge, regularities, spatial experiences and skills. In the result of abstraction a student is able to see the distinct lines, where they must be and how they could look like. Fulfilling such kind of tasks the manipulations happen mainly in the mental dimension. Running into difficulties to imagine any process or an object, it is very effective to use modern computer technologies, which allow visualizing both an object and a process itself in the space.

Concretization is understood as using of general knowledge not only for matching any definite example to corresponding regularity, but as using corresponding regularities in the fulfilling of definite task and forecasting the results. It is very important for students to know at least one of the methods to solve the task, to be able to use it in any task and understand the essence of these methods in space.

\section{Conclusions}

- Between the control group and experimental groups in Descriptive Geometry exist differences of incomprehension and understanding.

- Using of multimedia technologies in lectures gets better the students' spatial understanding.

- Using of special handouts helps students to break objects in basic elements and understand the theme better.

\section{Acknowledgements}

The authors gratefully acknowledge the funding from ERAF project $\mathrm{Nr}$. 2DP/2.1.1.2.0/10/APIA/VIAA/020 "Popularization of scientific activity of the Latvia University of Agriculture"

\section{References}

1. Волков И.П. (1992). Приобщение к творчеству. Минск: Нар.света.

2. Павлова А.А., Корзинова Е.И. (2003). Графика в средней школе. Москва: Владос.

3. Безрукова В.С. (2005). Педагогика. Проективная педагогика. Екатеринбург: Деловая книга.

4. Павлова А.А., Симоненко В.Д. (2005). Графика. Москва: Просвещение.

5. Бабанский Ю.К. (1988). Педагогика. Москва: Просвещение.

6. Грегори Р.Л. (1970). Глаз и мозг. Психология зрительного восприятия. Москва.

7. Якиманская И.С. (2004) Психологические основы математического образования. Москва: Академия.

8. Borns L., Ruso N. (2000). Psihologija. Rīga: RAKA. 